\title{
COMPARATIVE STUDY OF PREGNANCY RATE OF DAIRY COWS INSEMINATED WITH FRESH OR FROZEN-THAWED SEMEN
}

\author{
Jan Pytlík ${ }^{1}$ Luděk Stádník ${ }^{1}$ Jaromír Ducháček ${ }^{1}$, Radim Codl ${ }^{1}$ \\ ${ }^{1}$ Department of Animal Science, Faculty of Agrobiology, Food and Natural Resources, Czech University of Life \\ Sciences Prague, Kamýcká 129, 16500 Prague 6 - Suchdol, Czech Republic
}

Link to this article: https://doi.org/10.11118/actaun202068030573

Received: 24. 3. 2020, Accepted: 29. 4. 2020

To cite this article: PYTLÍK JAN, STÁDNÍK LUDĚK, DUCHÁČEK JAROMÍR, CODL RADIM. 2020. Comparative Study of Pregnancy Rate of Dairy Cows Inseminated with Fresh or Frozen-Thawed Semen. Acta Universitatis Agriculturae et Silviculturae Mendelianae Brunensis, 68(3): 573-581.

\begin{abstract}
The aim of this study was to investigate conception rates (CR) achieved with artificial insemination of Holstein cows using fresh or frozen insemination doses (ID). The synchronization protocols (Double-Ovsynch, Ovsynch, ReSynch) and pedometers were used to secure proper timing of artificial inseminations (AI). Total of 3979 inseminations data were recorded. Statistical analysis was performed using the SAS 9.3 package. For the evaluation of a CR, the effects of ID type, season, year, sire breed, lactation number and oestrus detection type, were analysed. Cows inseminated with fresh ID performed higher CR $(+4.86 \%$; $\mathrm{P}<0.05)$. Best pregnancy per artificial insemination (P/AI) success was observed during the winter season $(+11.82 \%$; $\mathrm{P}<0.01)$. Parity affected P/AI with primiparous having a greater $\mathrm{P} / \mathrm{AI}$ than multiparous cows $(\mathrm{P}<0.01)$. The least likelihood of pregnancy success matched up with ReSynch and the highest with Ovsynch protocol $(+7.7 \%$; $\mathrm{P}<0.05)$. In conclusion, fresh ID manifested superior CR over frozen-thawed semen under common conditions of Czech dairy farming. Similar or better P/AI was achieved when an automated activity monitoring were used rather than timed AI based on Ovsynch protocol, indicating a possible reduction in hormonal treatment applications without affecting fertility of high producing dairy cows.
\end{abstract}

Keywords: dairy cows, Holstein, artificial insemination, cryopreservation, insemination dose, frozenthawed semen, fresh semen, conception, synchronization, pedometer

\section{INTRODUCTION}

The artificial insemination (AI) is a method of choice how to secure conception in many farm animal species. Presently, in developed countries more than $90 \%$ of dairy cows are artificially inseminated (Ombelet and Van Robays, 2015). Two possible preservation techniques of insemination doses (ID) are currently available - in a fresh or in a frozen state (Morrell, 2011). The amount of annually produced cryopreserved ID exceeds several hundred millions, whereas production of fresh doses reaches only one-fifth of that number (Gordon, 2017). A standard preservation procedure consists of several different steps, namely, semen collection, evaluation, dilution, cooling, equilibration and freezing-thawing process in case of cryopreservation (Doležalová et al., 2016; Khalil et al., 2018). Both aforementioned ID production methods provide their own advantages and disadvantages. Advantages of fresh semen method include reduced number of spermatozoa per dose (increased sire utilization), reduced transportation and storage costs, increased insemination speed and safety in the field. Fresh-extended doses requires ten times less sperm number than frozen ID with no fertility decline presented. The ultimate 
disadvantage of fresh-extended ID is its short shelflife, when compared to frozen-thawed one (Bucher et al., 2009; Yang et al., 2018). Maximum life span of fresh ID is approximately 3 days long according to Murphy et al. (2016). On the other hand, the asset of cryopreserved dose is almost unlimited storage capability and so is its flexibility of use (Vishwanath and Shannon, 2000). Cryopreservation enables to apply an ID in an optional moment, yet this advantage comes at a cost with the viability of large amount of spermatozoa being reduced (Thurston et al., 2002). Spermatozoa which underwent a conventional process of cryopreservation deal with severe trouble to preserve their functions and features. Sperm cryopreservation leads to reduction of sperm motility and increases the percentage of spermatozoa with abnormal morphology (Celeghini et al., 2008; Pini et al., 2018). Deep freezing worsens a thermoresistance and a hypo-osmoticity resistance level of cryopreserved spermatozoa contrary to fresh-extended semen as well (BorgesSilva et al., 2016). The plasma membrane is the most vulnerable structure to a cryo-damage with various degrees of swelling, undulation or loss - 50\% of male germ cells have affected this organelle. Alongside the plasma membrane, other affected organelles are mitochondria, acrosome membrane and chromatin (Celeghini et al., 2008; Khalil et al., 2018). Despite the most refined freezing procedures, controlled freezing conditions and diluent modifications - the spermatozoa recovery after thawing is just over 50\% (Layek et al., 2016; Vishwanath, 2003). This large portion of nonviable spermatozoa, due to an increased reactive oxygen species production, plays a crucial role in a reduction of sperm fertility potential and its ability to co-develop healthy embryo (Roca et al., 2016). Besides the discussed harming effects, cryopreservation may lead to capacitation-like changes in spermatozoa which compromises sperm longevity (Aitken et al., 2015; Papa et al., 2015). This is in accordance with Richardson et al. (2017), who described a longer lifespan of fresh ID over frozen ones and therefore increased range in timing of an AI without affecting fertility. To ensure the best possible result after artificial insemination, dairy producers must manage precise heat detection, timing of insemination in relation to oestrus and proper handling of the insemination doses (Beran et al., 2013; Vincent et al., 2014). The most applied methods of oestrus detection and insemination timing in dairy farms globally are devices which monitor cow activity and various synchronization protocols (Caraviello et al., 2006; Saint-Dizier and ChastantMaillard, 2012; Saint-Dizier and Chastant-Maillard, 2018). There is an evidence of superior fertility of fresh doses compared to frozen-thawed ones in beef cows (Papa et al., 2015; Borges-Silva et al., 2016) however there is still a scarcity of published studies comparing AI outcomes in dairy cows with a fresh or frozen semen used (Borchardt et al., 2018). Therefore we engaged a study comparing the conception rates of dairy cows under the most common and widespread conditions. Such conditions are represented by high milk yield Holstein cattle herd, pedometers records and synchronization protocols for an oestrus detection and a timed AI respectively. The aim of the study was to investigate CR achieved with AI of Holstein cows using fresh or frozen ID. We worked on the assumption that fresh semen is exposed to less stressors and therefore has a higher probability to fertilize ovum, hence we expected superior outcomes of fresh ID over frozen doses.

\section{MATERIALS AND METHODS}

\section{Bulls and Semen Collection}

Bull semen used in this experiment was collected from breeding bulls kept in a private Artificial Insemination Centre. The semen of 39 bulls (34 Holsteins and 5 Blue Belgian bulls) was collected for the purpose of this work. The healthy donor bulls, ordinarily used for commercial purposes, were stabled under the identical and optimal conditions of handling, housing, feeding, watering and management during the entire period of the study. Ejaculates for production of fresh and frozen artificial ID were collected per standard operating procedure twice a week. The collection of the semen was provided with sterilized bovine artificial vagina warmed to $38{ }^{\circ} \mathrm{C}$. Obtained ejaculates were evaluated immediately after the collection process. The parameteres of volume of fresh semen (VOL, g), density of spermatozoa (DEN, $\times 10^{6} \mathrm{~mm}^{-3}$ ) and percentage of motile sperm (MOT) were appraised by only one trained technician. Only ejaculates corresponding to the initial parameters required by standard protocol (minimum VOL $1.5 \mathrm{~g}$, DEN $0.7 \times 10^{6} \mathrm{~mm}^{-3}$ and MOT 70\%) were processed afterwards. All ejaculates failing to meet stated criteria were excluded from the study.

\section{Semen Dilution and Processing}

The fresh semen was promptly diluted with egg-yolk free phospholipid extender Andromed $^{\circledR}$ (Minitüb GmbH, Tiefenbach, Germany) to a final spermatozoa concentration of $7.5 \times 10^{6}$ per one insemination dose (a long-term used standard of the collaborating Artificial Insemination Centre) after initial evaluation of fresh sperm quality. Semen was subsequently mixed up for 10 minutes at room temperature $\left(25^{\circ} \mathrm{C}\right)$ and then automatically loaded into $0.25 \mathrm{ml}$ straws using a computer-controlled filler (IMV Technologies, L'Aigle, France). Filled straws of each bull were divided into 2 groups, spread on the ramps and both cooled to $4-5{ }^{\circ} \mathrm{C}$ for 2 hours. The proportion of fresh AI doses produced from each ejaculate was based on the given request of each day, regularly one third of processed semen. After equilibration, the defined part of straws was 
transferred into a refrigerator or a cooling box and then transported at $4-5{ }^{\circ} \mathrm{C}$ to a farm staff member in the evening of the day of collection. During transport the fresh doses were placed in an insulated container equipped with cooling gel to maintain defined temperature. The remaining straws were used for the production of frozen doses and thus were frozen in a programmable freezer box Digitcool $^{\circledR}$ (IMV Cryo Bio System, L'Aigle, France). Straws sorted for freezing were then plunged into liquid nitrogen and remained cryopreserved in liquid nitrogen until the thawing and insemination procedure.

\section{Cows, Housing and Feeding}

The artificial inseminations were conducted in one commercial farm located in Central Bohemian Region, from September 2015 to October 2016. Farm is situated 26 kilometers away from the Artificial Insemination Centre. Holstein cows $(n=1150)$ were milked three times a day approximately $8 \mathrm{~h}$ apart in a $2 \times 21$ side-by-side parlour. Animals were fed twice a day a total mixed ration consisting of corn and alfalfa silage as a forage, with brewers' grains, soybean or rapeseed meal-based concentrate, supplements and minerals to fulfil optimal balanced diet for dairy cows. Cows were housed in freestall barns on a compost bedding and had ad libitum access to feed and water. Slurry removal was provided by rope scrapers every 1 hour. Barns were equipped with fans and sprinklers that were automatically activated when temperature inside the barn reached heat stress level. Barn had an open side walls equipped with automatic controlled curtains as well. The rolling herd average was $11,277 \mathrm{~kg}$ with $3.69 \%$ fat and $3.34 \%$ protein (standard 305 d lactation) for the entire herd during the time period of this experiment.

\section{Reproductive Management}

Only cows in lactation took part in this experiment. There were 2 different ways of oestrus detection use of synchronization protocols (Double-Ovsynch, Ovsynch and ReSynch) or pedometers. Inseminations were carried out by 1 AI technician using semen straws with fresh or frozen-thawed semen. A decision on which protocol was used for a particular animal was made by the cow manager and was based on the daily milk yield progress, body condition score and the result of a previous reproductive tract ultrasonographic examination. The AI was performed on precize time schedule according to chosen protocol, in case of hormonal treatment. In case of pedometer heat detection there were 2 possible time spans of an artificial insemination procedure - after morning or afternoon milking. Cows treated with Ovsynch protocol received 2 injections of Gonadotropin Releasing Hormone (GnRH) on day 0 and 10 (56 hours after $\mathrm{PGF}_{2 \mathrm{a}}$ ). In this case an insemination was performed 12-14 hours after second GnRH injection. Double-Ovsynch protocol involved treatment with GnRH on day 0, followed 7 days later by PGF, a GnRH treatment 3 days later and eventually by the Ovsynch synchronization as mentioned above after 7 days of previous GnRH injection. The first part of ReSynch protocol was identical to Ovsynch. Then there were a GnRH treatment after 32 days since the Ovsynch TAI. Cows diagnosed not pregnant after 7 days post last hormonal injection were resynchronized again by the aforementioned Ovsynch protocol. Therefore resynchronizing deals with lactating dairy cows that failed to conceive to a prior TAI. A transrectal ultrasonography was performed 39 days after TAI for the purpose of a gestation confirmation or a disapproval.

\section{Data and Statistical Analyses}

The data were analyzed by SAS software (Statistical Analysis System, Version 9.3, 2011). The conception rate was a main parameter in this study. Overall, 3979 artificial inseminations were performed during this work and data of these services were used for statistical analyses. A total of 1150 fresh and 2829 frozen-thawed semen inseminations were performed during the period of this study. This resulted in 1198 conceptions and 2781 conception failures. Avalaible data for analysis included type of insemination dose, insemination season, year, sire identity, sire breed, lactation number, oestrus detection type and conception success. Procedure REG, method STEPWISE was used for choosing best model evaluation for observed parameters. Effect of lactation number was adapted on 3 levels ( $1^{\text {st }}, 2^{\text {nd }}, 3^{\text {rd }}$ and other lactations) as the frequency of lactation number higher than 3 was lower. Procedure GLM (Multi-factor Analysis of Variance) was used for an evaluation of individual effect. Deatiled evaluation of differences between effect levels were done with Tukey-Kramer test.

The model equation used for an evaluation was as follows:

$$
\begin{aligned}
Y_{i j k l m n o}= & \mu+I D_{i}+S E A_{j}+Y E A R_{k}+B R E E D_{l}+ \\
& +L A C_{m}+D E T_{n}+e_{i j k l m n o},
\end{aligned}
$$

where:

$Y_{i j k l m n o}$..........dependent variable (conception rate);

$\mu$...................mean value of dependent variable;

$I D_{i}$..................... fixed effect of insemination dose type $(i=1$, fresh, $n=1150 ; i=2$, frozen, $n=2829$ );

$S E A_{j} \ldots . . . . . . . .$. fixed effect of season $(j=1$, spring, $n=751$; $j=2$, summer, $n=624 ; j=3$, autumn, $n=1551 ; j=4$, winter, $n=1053)$;

$Y E A R_{k} \ldots \ldots . . .$. fixed effect of year $(k=2015, n=951$; $k=2016, n=3028$ );

$B R E E D_{l}$...... fixed effect of sire breed $(l=1$, Belgian Blue, $n=1354 ; l=2$, Holstein, $n=2625$ );

$L A C_{m}$...........fixed effect of parity lactation number ( $m=1^{\text {st }}, n=1357 ; m=2^{\text {nd }}, n=1185 ; m=3^{\text {rd }}$ and other, $n=1437$ ); 
$D E T_{n}$...........fixed effect of oestrus detection type $(n=1$, Double-Ovsynch, $n=538 ; n=2$, Ovsynch, $n=546 ; n=3$, pedometer, $n=2000 ; n=4$, ReSynch, $n=895$ );

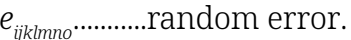

The significance levels $\mathrm{P}<0.05$ and $\mathrm{P}<0.01$ were used to evaluate the differences between groups.

\section{RESULTS}

For the evaluation of a conception rate, the effects of ID type, season, year, sire breed, lactation number and oestrus detection type, were input into the model equation. The model equation was significant $(\mathrm{P}<0.001)$ and explained $3.44 \%$ of the variance of a conception rate. All described effects were statistically significant $(\mathrm{P}<0.01)$, except the sire breed effect. Detailed evaluation of selected effects and their influence of a conception rate is reported in Tab. I. Cows inseminated with fresh insemination doses scored higher conception rate compared to AI success with frozen-thawed ID by $4.86 \%$. There was found a conclusive difference at level of significance $(\mathrm{P}<0.05)$ between both types of ID. The conception rate was changed throughout the year as the seasons passed. The best insemination rate matches with winter (39.03\%), followed by spring (34.98\%), autumn (30.71\%) and summer (27.21\%). Between some evaluated seasons were proved statistically significant differences - detailed information can be seen in Tab. I. Fig. 1 refers to pregnancy success rate of both types of ID throughout the year. Yet the differences were insignificant, trends of improved P/AI when fresh semen was deposited are evident. Improved conception success was evaluated after deposition of Holstein sires ID in comparison with ID of Belgium Blue bulls by 3.25\% ( $<$ < 0.05). Downward tendency was observed in lactation number effect the higher lactation number, the lower conception success. Cows on their first lactation scored the highest values of conception rate (38.93\%), ensued by milking cows on their second lactation (32.64\%) and animals on their third and others lactations (27.38\%). Differences at level of significance $(\mathrm{P}<0.01)$ were among others observed between primiparous and cows on their second or third and other lactations respectively. Each oestrus detection type reached a different value of conception success. The lowest probability of conception was connected with ReSynch treatment (28.93\%) and Double-Ovsynch (31.46\%). The best results performed utilization of pedometer data (34.90\%) and Ovsynch protocol (36.64\%). The difference between the most and the least successful treatment was 7.71\%. Statistically significant difference was proved $(\mathrm{P}<0.05)$ between Ovsynch and ReSynch and pedometer and ReSynch treatment.

\section{DISCUSSION}

Semen cryopreservation represents one of the most important elements in genetic progress of dairy cattle populations over the last decades. Yet this procedure has some flaws. The main problem of cryopreserved ID are irreversible changes of sperm function and morphology which male gametes underwent during the freezing and thawing process (Khalil et al., 2018). Those changes are frequently manifested in lower conception rates when the ID is deposited frozen rather than fresh (Xu, 2014). Semen cryopreservation is therefore considered suboptimal due to lower fertility when compared to fresh semen (Crespilho et al., 2012). However, some studies, like Buckley et al. (2003), Saha et al. (2014) and Maicas et al. (2019) described reduced likelihood of pregnancy with the use of fresh semen compared to frozen-thawed semen. For instance, a lower conception rate of fresh (54.9\%) doses compared to frozen-thawed $(62.75 \%)$ ones was observed in the experiment carried out by Saha et al. (2014), yet only 102 animals were included in this study. Large portions of studies like Bucher et al. (2009), Crespilho et al. (2014), Xu (2017) and Yang et al. (2018) reported comparable P/AI whether ID was deposited fresh or frozen. Over a decade-long study conducted by Yang et al. (2018) did not find a difference in pregnancy outcomes of lactating cows (P/AI of $67.6 \%$ with fresh and $67.8 \%$ with frozen ID). There

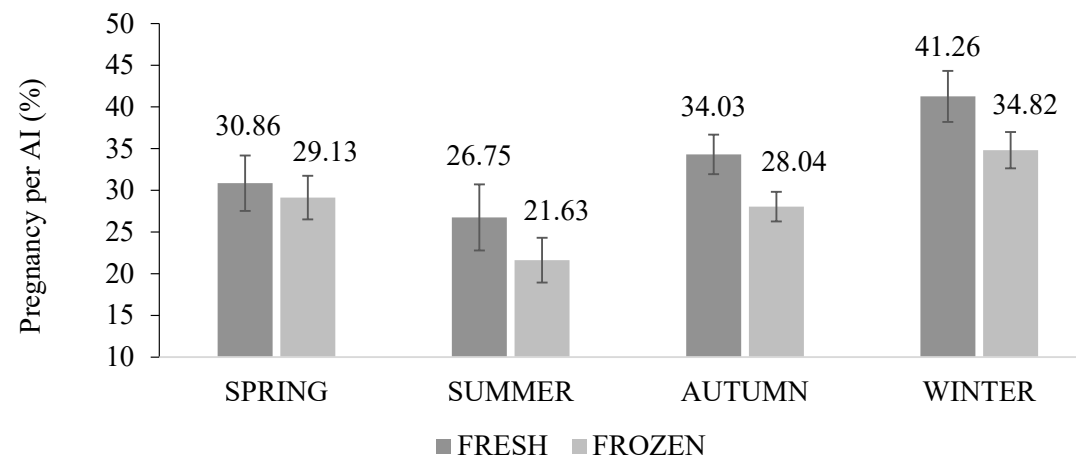

1: Pregnancy per AI (least-squares means \pm standard error of the mean) of Holstein cows inseminated by either fresh or frozen-thawed insemination dose during different seasons of the year 
I: Conception rates (least-squares means \pm standard error of the mean) of Holstein cows as affected by evaluated effects

\begin{tabular}{|c|c|}
\hline \multirow{2}{*}{ Effect } & Conception rate (\%) \\
\hline & $\mathrm{LSM} \pm \mathrm{SEM}$ \\
\hline \multicolumn{2}{|c|}{ Insemination dose type } \\
\hline Fresh ID & $35.41 \pm 1.533^{\mathrm{a}}$ \\
\hline Frozen ID & $30.55 \pm 1.338^{b}$ \\
\hline \multicolumn{2}{|c|}{ Season } \\
\hline Spring & $34.98 \pm 1.999^{\AA}$ \\
\hline Summer & $27.80 \pm 2.093^{\text {В,С,Е }}$ \\
\hline Autumn & $30.71 \pm 1.325^{\mathrm{D}}$ \\
\hline Winter & $39.03 \pm 1.596^{\mathrm{F}}$ \\
\hline \multicolumn{2}{|c|}{ Year } \\
\hline 2015 & $37.23 \pm 1.846^{\mathrm{A}}$ \\
\hline 2016 & $28.74 \pm 1.032^{\mathrm{B}}$ \\
\hline \multicolumn{2}{|c|}{ Sire breed } \\
\hline Belgium Blue & $31.36 \pm 1.595^{\mathrm{a}}$ \\
\hline Holstein & $34.61 \pm 1.226^{b}$ \\
\hline
\end{tabular}

\begin{tabular}{lc}
\hline \multicolumn{2}{c}{ Lactation number } \\
\hline Lactation I & $38.93 \pm 1.531^{\mathrm{A}, \mathrm{C}}$ \\
Lactation II & $32.64 \pm 1.644^{\mathrm{B}, \mathrm{E}}$ \\
Lactation III+ & $27.38 \pm 1.475^{\mathrm{D}, \mathrm{F}}$ \\
\hline \multicolumn{2}{c}{ Oestrus detection type } \\
\hline Double-Ovsynch & $31.46 \pm 2.261$ \\
Ovsynch & $36.63 \pm 2.192^{\mathrm{a}}$ \\
Pedometer & $34.90 \pm 1.286^{\mathrm{C}}$ \\
ReSynch & $28.93 \pm 1.660^{\mathrm{b}, \mathrm{D}}$ \\
\hline Differn
\end{tabular}

Different letters (A-B, C-D...) in columns means statistical significance $\mathrm{P}<0.01$.

Different letters (a-b, c-d...) in columns means statistical significance $\mathrm{P}<0.05$.

is a speculation that both application forms may obtain similar conception rates when systems are optimised. Comparable pregnancy rates (51.5\% and 50.4\%) were also obtained by Bucher et al. (2009) in commercial beef cows treated with hormonal synchronization protocol whether the insemination doses were used fresh $\left(n=736 ; 3 \times 10^{6}\right.$ sperm/straw) or frozen ( $=719 ; 20 \times 10^{6} \mathrm{sperm} /$ straw), even with a $85 \%$ reduction of sperm numbers in the fresh semen $\left(3 \times 10^{6}\right.$ sperm/straw) as compared to the frozen semen $\left(20 \times 10^{6} \mathrm{sperm} / \mathrm{straw}\right)$. In case of same sperm concentration $\left(25 \times 10^{6} \mathrm{sperm} /\right.$ straw) BorgesSilva et al. (2016) observed favourable effect of fresh doses over the frozen-thawed ones on pregnancy success rate ( $n=430 ; 59.9 \%$ vs. $n=408,49.4 \%)$ in beef cows ( $n=838$ ), which were also submitted to fixed-time artificial insemination program. The similar findings of improved fertility of fresh ID were obtained in a study comparing conception success in Nelore lactating cows $(n=349)$ treated with synchronization protocol whether fresh or frozen semen was deposited during fixed-time artificial insemination. Pregnancy rates were $61.49 \%$ and $45.71 \%$ ( $\mathrm{P}<0.05$ ), respectively, for the fresh or cryopreserved semen (Crespilho et al., 2012). Superior conception outcomes of fresh ID are described in a recent study from Germany by Borchardt et al. (2018), where the effect of P/AI was evaluated using fresh $\left(10 \times 10^{6}\right.$ sperm/straw $)$ or frozen $\left(20 \times 10^{6}\right.$ sperm/straw $)$ semen in indoor stabled high producing dairy cows submitted to TAI protocols. Fresh semen resulted in a greater pregnancy rate $(32.3 \%)$ compared to frozen semen (28.6\%) under Ovsynch treatment, which is consistent with the results obtained in the present study, although we used lower concentration of $7.5 \times 10^{6}$ sperm per straw in both application forms. Similarly, as in our results, the conception rate of conventional semen for Holstein cows was also found to be $30 \%$ in longtermed detailed study by (Norman et al., 2010).

Results from the current study also show that CR fluctuated throughout the year, with the nadir during the summer season. Conception rate of lactating dairy cows in the moderate climate of Central Europe is highly affected by heat stress, which mainly occurs from June to September (Schüller et al., 2014). Fertility decline lies in metabolic and physiological changes which animals face during heat stress. A reduced feed intake, which may compromise the energy balance, modified hormonal secretion, which, for instance, affects interval between oestrus and ovulation, risk of ovaries pathologies or even worsened oestrus expression and follicle size belong amongst the most significant difficulties in summer subfertility (Honig et al., 2016; Schüller et al., 2016; De Rensis et al., 2017). Conception rates are reduced when cows are exposed to high heat loads either before or after service - particularly important is a whole week from the day of service to 6 days after AI (Morton et al., 2007). Even periods of mild hot temperatures are responsible for decreased ovarian activity, which hamper success of AI according to Bezdíček et al. (2019). De Rensis et al. (2017) suggest that also a change in photoperiod may affect fertility through altered melatonin production and its effect on Gonadotropin-releasing hormone pulses and Hypothalamic-Pituitary-Ovarian axis, respectively. Results of our study correspond with the changing sum of temperatures during the year and are in compliance with previous works of Sartori et al. (2002), Guo et al. (2004), Demetrio et al. (2007) and Abdel Aziz and Abdel-Wahab (2017) where cows demonstrated higher CR during winter or spring than cows in summer season and are also in accordance with López-Gatius (2003) who described cooler seasons as a stabilizators of fertility decline. 
The sire breed effect was included in data cleansing, yet evaluated with no statistical significance. Neither this effect was an objective of our study nor of large importance, hence we do not address it in the discussion. In the lactating cows in our study, P/AI decreased with increasing lactation number, which was expected due to the significant influence of high milk production on a fertility performance in cows. It is well documented that the physiological load, disease and infection risk of multiparous cows differs from primiparous and that cows with a greater lactation number are less likely to conceive (Roche et al., 2009). Results of our study are in compliance with previous works of Chebel et al. (2004), Sales et al. (2016), Machado et al. (2017), Abdel Aziz and Abdel-Wahab (2017) and Denis-Robichaud et al. (2018).

Conception rate of high producing dairy cows is low due to a declined fertility level, limited oestrus manifestations and therefore worsened oestrus detection (López-Gatius, 2003). More complicated and worsened oestrus detection facilitates the introduction of synchronization treatments in dairy farms, since there is no need of oestrus detection afterwards (Azevedo et al., 2014). To our knowledge, there is no other study comparing P/AI with fresh or frozen ID whether Ovsynch, Double Ovsynch, Re-Synch protocol or pedometer data records were used. Majority of peer-reviewed literature deal with no more than 2 oestrus detection systems or timed AI protocols or its various modifications respectively. Therefore we are not able to fully compare our results with previous studies, yet there are some partial findings which can be observed.
In the study by Neves et al. (2012) the overall reproductive performance was found to be similar between management based on automated activity monitoring (AAM) and a synchronization program for TAI, including Ovsynch, Presynch or Co-Synch. Double-Ovsynch treatment appears to increase CR to the maximum currently attainable level (Souza et al., 2008; Herlihy et al., 2012; Neves et al., 2012; Santos et al., 2017). Hence our results are not consistent with Denis-Robichaud et al. (2018) who reported improved CR if Double Ovsynch protocol was administered (36.3\%) rather than application of the AAM system (32\%). Dissimilar results to our findings were also found in a work of Giordano et al. (2015) who described better P/AI after AAM than TAI after Ovsynch protocol. The results of the current study indicate similar or better CR when an automated activity monitoring is used rather than timed AI based on Ovsynch protocol in high producing dairy cows. Giordano et al. (2012) observed a favourable effect of Double Ovsynch protocol over ReSynch treatment, which is consistent with our observations. Surprisingly, a superior CR after Double Ovsynch was not observed in our study as this protocol achieved one of the lowest values of $\mathrm{P} /$ AI in the work. A possible explanation for the lessthan-expected P/AI of the Double-Ovsynch in our study is less-than perfect compliance to the injection schedule. We further conclude, that the worst performance of used timed AI protocol is caused by metabolic disorder or rather general subfertility, since animals treated with ReSynch already failed in one AI attempt after Ovsynch treatment.

\section{CONCLUSION}

An artificial insemination with fresh semen is not still a standard procedure in most countries. Our work provides scientific contribution of its usefulness in common conditions of Czech dairy farming and simultaneously adds another study which deals with P/AI when fresh or frozen-thawed semen is deposited in dairy cows. A statistically significant difference in a conception rate in favour of fresh ID over frozen-thawed semen was proved. Despite advantages of fresh semen (conception rate improvement, optimised use of genetically superior bulls or bulls which do not perform well during cryopreservation, lower cost of semen processing and storage, practicality for fixed timed AI) there is still unsolved problem of fresh ID limited shelf-life, which hamper larger utilization, particularly in farms with nonparticipation in synchronization protocols. Fresh insemination doses may be an efficient alternative choice in conventional AI procedure afterwards. Hence a constant search for a technological breakthrough which would extend the 3 days-long application window must continue. Results of the study proved that the season of the insemination event affects conception success rate with lowest probability during summer and highest in winter months of the year. Parity affected P/AI with primiparous having a greater P/AI than multiparous cows. Results of current study also indicate similar or better CR when an automated activity monitoring is used rather than timed AI based on Ovsynch protocol and therefore dispute a contribution of herd-level hormonal treatment applications and thus indicate possible reduction in hormonal treatment applications without affecting fertility of high producing dairy cows. We suggest initiating an analogous study with several different lower concentrations of sperm per ID to evaulate specific benefits of fresh insemination doses. Replication of our study in multiple herds will be important to validate our research findings in a larger population of dairy cows. 
Acknowledgements

This research was funded by an "S" grant of the MŠMT and Project NAZV No. QK1910242 of the MZe of the Czech Republic. We are grateful to Ondřej Martínek for English language correction of the manuscript.

\section{REFERENCES}

ABDEL AZIZ, R. L. and ABDEL-WAHAB, A. 2017. Reproductive responses of primiparous and multiparous Holstein cows submitted to presynch-ovsynch protocol. Beni-Suef University Journal of Basic and Applied Sciences, 6(2): 149-153.

AITKEN, R. J., BAKER, M. A. and NIXON, B. 2015. Are sperm capacitation and apoptosis the opposite ends of a continuum driven by oxidative stress? Asian Journal of Andrology, 17(4): 633-639.

AZEVEDO, C., MAIA, I., CANADA, N. and SIMÕES, J. 2014. Comparison of fertility, regular returnsto-estrus, and calving interval between Ovsynch and CO-synch + CIDR protocols in dairy cows. Theriogenology, 82(6): 910-914.

BERAN, J., STÁDNÍK, L., DUCHÁČEK, J., OKROUHLÁ, M., DOLEŽALOVÁ, M., KADLECOVÁ, V. and PTÁČEK, M. 2013. Relationships among the cervical mucus urea and acetone, accuracy of insemination timing, and sperm survival in Holstein cows. Animal Reproduction Science, 142(1-2): 28-34.

BEZDÍČEK, J., STÁDNÍK, L., MAKAREVICH, A., KUBOVIČOVÁ, E., LOUDA, F., HEGEDÜŠOVÁ, Z. and HOLÁSEK, R. 2019. The effect of mild temperature stress on the ovarian activity in cows. Journal of Microbiology, Biotechnology and Food Sciences, 9: 639-642.

BORCHARDT, S., SCHÜLLER, L., WOLF, L., WESENAUER, C. and HEUWIESER, W. 2018. Comparison of pregnancy outcomes using either an Ovsynch or a Cosynch protocol for the first timed AI with liquid or frozen semen in lactating dairy cows. Theriogenology, 107: 21-26.

BORGES-SILVA, J. C., SILVA, M. R., MARINHO, D. B., NOGUEIRA, E., SAMPAIO, D. C., OLIVEIRA, L. O. F., ABREU, U. G. P., MOURÃO, G. B. and SARTORI, R. 2016. Cooled semen for fixed-time artificial insemination in beef cattle. Reproduction, Fertility and Development, 28(7): 1004-1008.

BUCHER, A., KASIMANICKAM, R., HALL, J. B., DEJARNETTE, J. M., WHITTIER, W. D., KÄHN, W. and XU, Z. 2009. Fixed-time AI pregnancy rate following insemination with frozen-thawed or freshextended semen in progesterone supplemented CO-Synch protocol in beef cows. Theriogenology, 71(7): 1180-1185

BUCKLEY, F., MEE, J., O'SULLIVAN, K., EVANS, R., BERRY, D. and DILLON, P. 2003. Insemination factors affecting the conception rate in seasonal calving Holstein-Friesian cows. Reproduction, Nutrition, Development, 43(6): 543-555.

CARAVIELlO, D. Z., WEIGEL, K. A., FRICKE, P. M., WiltBANK, M. C., FlORENT, M. J., COOK, N. B., NORDLUND, K. V., ZWALD, N. R. and RAWSON, C. L. 2006. Survey of management practices on reproductive performance of dairy cattle on large US commercial farms. Journal of Dairy Science, 89(12): 4723-4735.

CELEGHINI, E. C. C., DE ARRUDA, R. P., DE ANDRADE, A. F. C., NASCIMENTO, J., RAPHAEL, C. F. and RODRIGUES, P. H. M. 2008. Effects that bovine sperm cryopreservation using two different extenders has on sperm membranes and chromatin. Animal Reproduction Science, 104(2-4): 119-131.

CHEBEL, R. C., SANTOS, J. E. P., REYNOLDS, J. P., CERRI, R. L. A., JUCHEM, S. O. and OVERTON, M. 2004. Factors affecting conception rate after artificial insemination and pregnancy loss in lactating dairy cows. Animal Reproduction Science, 89: 239-255.

CRESPILHO, A. M., NICHI, M., GUASTI, P. N., FREITAS-DELL'AQUA, C. P., SÁ FILHO, M. F., MAZIERO, R. R., DELL'AQUA, J. A. and PAPA, F. O. 2014. Sperm fertility and viability following 48 h of refrigeration: Evaluation of different extenders for the preservation of bull semen in liquid state. Animal Reproduction Science, 146(3-4): 126-133.

CRESPILHO, A. M., PAPA, F. O., SANTOS, M. P. and FILHO, M. F. S. 2012. Use of cooled bull semen as a strategy to increase the pregnancy rate in fixed-time artificial insemination programs-case report. American Journal of Animal and Veterinary Sciences, 7(4): 175-179.

DE RENSIS, F., LOPEZ-GATIUS, F., GARCÍA-ISPIERTO, I., MORINI, G. and SCARAMUZZI, R. J. 2017. Causes of declining fertility in dairy cows during the warm season. Theriogenology, 91: 145-153.

DEMETRIO, D. G. B., SANTOS, R. M., DEMETRIO, C. G. B. and VASCONCELOS, J. L. M. 2007. Factors affecting conception rates following artificial insemination or embryo transfer in lactating Holstein cows. Journal of Dairy Science, 90(11): 5073-5082.

DENIS-ROBICHAUD, J., CERRI, R. L. A., JONES-BITTON, A. and LEBLANC, S. J. 2018. Performance of automated activity monitoring systems used in combination with timed artificial insemination compared to timed artificial insemination only in early lactation in dairy cows. Journal of Dairy Science, 101(1): 624-636. 
DOLEŽALOVÁ, M., STÁDNÍK, L., BINIOVÁ, Z., DUCHÁČEK, J. and STUPKA, R. 2016. Equilibration and freezing interactions affecting bull sperm characteristics after thawing. Czech Journal of Animal Science, 61(11): 515-525.

GIORDANO, J. O., STANGAFERRO, M. L., WIJMA, R., CHANDLER, W. C. and WATTERS, R. D. 2015. Reproductive performance of dairy cows managed with a program aimed at increasing insemination of cows in estrus based on increased physical activity and fertility of timed artificial inseminations. Journal of Dairy Science, 98: 2488-2501.

GIORDANO, J. O., WILTBANK, M. C., GUENTHER, J. N., PAWLISCH, R., BAS, S., CUNHA, A. P. and FRICKE, P. M. 2012. Increased fertility in lactating dairy cows resynchronized with Double-Ovsynch compared with Ovsynch initiated 32 d after timed artificial insemination. Journal of Dairy Science, 95(2): 639-653. GORDON, I. 2017. Reproductive Technologies in Farm Animals. $2^{\text {nd }}$ Edition. CABI.

GUO, K., RUSSEK-COHEN, E., VARNER, M. A. and KOHN, R. A. 2004. Effects of milk urea nitrogen and other factors on probability of conception of dairy cows. Journal of Dairy Science, 87: 1878-1885.

HERLIHY, M. M., GIORDANO, J. O., SOUZA, A. H., AYRES, H., FERREIRA, R. M., KESKIN, A., NASCIMENTO, A. B., GUENTHER, J. N., GASKA, J. M., KACUBA, S. J., CROWE, M. A., BUTLER, S. T. and WILTBANK, M. C. 2012. Presynchronization with Double-Ovsynch improves fertility at first postpartum artificial insemination in lactating dairy cows. Journal of Dairy Science, 95(12): 7003-7014.

HONIG, H., OFER, L., ELBAZ, M., KAIM, M., SHINDER, D. and GERSHON, E. 2016. Seasonal and parity effects on ghrelin levels throughout the estrous cycle in dairy cows. General and Comparative Endocrinology, 235: 64-69.

KHALIL, W. A., EL-HARAIRY, M. A., ZEIDAN, A. E. B., HASSAN, M. A. E. and MOHEY-ELSAEED, O. 2018. Evaluation of bull spermatozoa during and after cryopreservation: Structural and ultrastructural insights. International Journal of Veterinary Science and Medicine, 6: S49-S56.

LAYEK, S. S., MOHANTY, T. K., KUMARESAN, A. and PARKS, J. E. 2016. Cryopreservation of bull semen: Evolution from egg yolk based to soybean based extenders. Animal Reproduction Science, 172: 1-9.

LÓPEZ-GATIUS, F. 2003. Is fertility declining in dairy cattle? A retrospective study in northeastern Spain. Theriogenology, 60: 89-99.

MACHADO, V. S., NEVES, R., LIMA, F. S. and BICALHO, R. C. 2017. The effect of Presynch-Ovsynch protocol with or without estrus detection on reproductive performance by parity, and the longterm effect of these different management strategies on milk production, reproduction, health and survivability of dairy cows. Theriogenology, 93: 84-92.

MAICAS, C., HUTCHINSON, I. A., KENNEALLY, J., GRANT, J., CROMIE, A. R., LONERGAN, P. and BUTLER, S. T. 2019. Fertility of fresh and frozen sex-sorted semen in dairy cows and heifers in seasonalcalving pasture-based herds. Journal of Dairy Science, 102: 10530-10542.

MORRELL, J. 2011. Artificial Insemination: Current and Future Trends. In: MANAFI, M. (Ed.). Artificial Insemination in Farm Animals. Intech Open.

MORTON, J. M., TRANTER, W. P., MAYERS, D. G. and JONSSON, N. N. 2007. Effects of environmental heat on conception rates in lactating dairy cows: Critical periods of exposure. Journal of Dairy Science, 90: 2271-2278.

MURPHY, C., HOLDEN, S. A., MURPHY, E. M., CROMIE, A. R., LONERGAN, P. and FAIR, S. 2016. The impact of storage temperature and sperm number on the fertility of liquid-stored bull semen. Reproduction, Fertility and Development, 28(9): 1349-1359.

NEVES, R. C., LESLIE, K. E., WALTON, J. S. and LEBLANC, S. J. 2012. Reproductive performance with an automated activity monitoring system versus a synchronized breeding program. Journal of Dairy Science, 95(10): 5683-5693.

NORMAN, H. D., HUTCHISON, J. L. and MILLER, R. H. 2010. Use of sexed semen and its effect on conception rate, calf sex, dystocia, and stillbirth of Holsteins in the United States. Journal of Dairy Science, 93(8): 3880-3890.

OMBELET, W. and VAN ROBAYS, J. 2015. Artificial insemination history: hurdles and milestones. Facts, Views \& Vision in ObGyn, 7(2): 137-143.

PAPA, P. M., MAZIERO, R. D., GUASTI, P. N., JUNQUEIRA, C. R., FREITAS-DELL'AQUA, C. P., PAPA, F. O., VIANNA, F. P., ALVARENGA, M. A., CRESPILHO, A. M. and DELL'AQUA, J. A. 2015. Effect of glycerol on the viability and fertility of cooled bovine semen. Theriogenology, 83(1): 107-113.

PINI, T., LEAHY, T. and DE GRAAF, S. P. 2018. Sublethal sperm freezing damage: Manifestations and solutions. Theriogenology, 118: 172-181.

RICHARDSON, B. N., LARIMORE, E. L., WALKER, J. A., UTT, M. D., DEJARNETTE, J. M. and PERRY, G. A. 2017. Comparison of fertility of liquid or frozen semen when varying the interval from CIDR removal to insemination. Animal Reproduction Science, 178: 61-66.

ROCA, J., PARRILlA, I., GIL, M. A., CUELLO, C., MARTINEZ, E. A. and RODRIGUEZ-MARTINEZ, H. 2016. Non-viable sperm in the ejaculate: Lethal escorts for contemporary viable sperm. Animal Reproduction Science, 169: 24-31. 
ROCHE, J. R., FRIGGENS, N. C., KAY, J. K., FISHER, M. W., STAFFORD, K. J. and BERRY, D. P. 2009. Body condition score and its association with dairy cow productivity, health, and welfare. Journal of Dairy Science, 92: 5769-5801.

SAHA, R., ASHRAF, A., RAHMAN, Z. and ADV, J. A. S. 2014. Comparative Study on Conception Rate of Cow in Using Frozen and Liquid Semen. Journal of Animal Science Advances, 4(3): 749-772.

SAINT-DIZIER, M. and CHASTANT-MAILLARD, S. 2012. Towards an Automated Detection of Oestrus in Dairy Cattle. Reproduction in Domestic Animals, 47(6): 1056-1061.

SAINT-DIZIER, M. and CHASTANT-MAILLARD, S. 2018. Potential of connected devices to optimize cattle reproduction. Theriogenology, 112: 53-62.

SALES, J. N. S., BOTTINO, M. P., SILVA, L. A. C. L., GIROTTO, R. W., MASSONETO, J. P. M., SOUZA, J. C. and BARUSELLI, P. S. 2016. Effects of eCG are more pronounced in primiparous than multiparous Bos indicus cows submitted to a timed artificial insemination protocol. Theriogenology, 86: 2290-2295.

SANTOS, V. G., CARVALHO, P. D., MAIA, C., CARNEIRO, B., VALENZA, A. and FRICKE, P. M. 2017. Fertility of lactating Holstein cows submitted to a Double-Ovsynch protocol and timed artificial insemination versus artificial insemination after synchronization of estrus at a similar day in milk range. Journal of Dairy Science, 100(10): 8507-8517.

SARTORI, R., SARTOR-BERGFELT, R., MERTENS, S. A., GUENTHER, J. N., PARRISH, J. J. and WILTBANK, M. C. 2002. Fertilization and early embryonic development in heifers and lactating cows in summer and lactating and dry cows in winter. Journal of Dairy Science, 85: 2803-2812.

SCHÜLLER, L.-K., BURFEIND, O. and HEUWIESER, W. 2016. Effect of short- and long-term heat stress on the conception risk of dairy cows under natural service and artificial insemination breeding programs. Journal of Dairy Science, 99(4): 2996-3002.

SCHÜLLER, L. K., BURFEIND, O. and HEUWIESER, W. 2014. Impact of heat stress on conception rate of dairy cows in the moderate climate considering different temperature-humidity index thresholds, periods relative to breeding, and heat load indices. Theriogenology, 81(8): 1050-1057.

SOUZA, A. H., AYRES, H., FERREIRA, R. M. and WILTBANK, M. C. 2008. A new presynchronization system (Double-Ovsynch) increases fertility at first postpartum timed AI in lactating dairy cows. Theriogenology, 70(2): 208-215.

THURSTON, L. M., WATSON, P. F. and HOLT, W. V. 2002. Semen cryopreservation: A genetic explanation for species and individual variation? Cryo-Letters, 23(4): 255-262.

VINCENT, P., UNDERWOOD, S. L., DOLBEC, C., BOUCHARD, N., KROETSCH, T. and BLONDIN, P. 2014. Bovine Semen Quality Control in Artificial Insemination Centers. Bovine Reproduction, 9(3): 153165.

VISHWANATH, R. 2003. Artificial insemination: The state of the art. Theriogenology, 59(2): 571-584.

VISHWANATH, R. and SHANNON, P. 2000. Storage of bovine semen in liquid and frozen state. Animal Reproduction Science, 62(1-3): 23-53.

XU, Z. Z. 2014. Application of liquid semen technology improves conception rate of sex-sorted semen in lactating dairy cows. Journal of Dairy Science, 97(11): 7298-7304.

XU, Z. Z. 2017. Effect of time of artificial insemination after oestrus detection on non-return rate of lactating dairy cows on pasture. New Zealand Veterinary Journal, 65(3): 119-123.

YANG, D. H., STANDLEY, N. T. and XU, Z. Z. 2018. Application of liquid semen technology under the seasonal dairy production system in New Zealand. Animal Reproduction Science, 194: 2-10.

Contact information

Jan Pytlík: pytlik@af.czu.cz

Luděk Stádník: stadnik@af.czu.cz

Jaromír Ducháček: duchacek@af.czu.cz

Radim Codl: codl@af.czu.cz 